\title{
Anticausatives with passives of subordinate intransitive clauses in Xitsonga
}

\section{Madala Crous Hlungwani}

MER Mathivha Centre for African Languages, Arts and Culture, University of Venda, Thohoyandou, South Africa E-mail: Crous.hlungwane@univen.ac.za

\begin{abstract}
Literature shows that anticausatives have been well investigated in European languages such as English, German, and Greek. However, this is not the case with African languages, particularly Bantu languages such as Xitsonga. The available evidence suggests that there remain unanswered questions about anticausatives across languages. This article, therefore, is an attempt to reduce this knowledge gap by providing a perspective that seems to have been overlooked in previous studies, namely how anticausatives and passives can interact and complement each other in a single construction. In Xitsonga, anticausatives are marked by the presence of neuter-passive morpheme -ek- on the verb, for example, -hlanhl-a 'smash to pieces' $>$-hlanhl-ek-ile 'smashed to pieces', while the passives are marked by the morpheme -iw-, for example, -hlanhl-iw-ile 'smashed to pieces'. The anticausatives in this paper occur as the main clause while the passives occur as the subordinate hikuva 'because' reason clause. The main concern of the present paper is to determine the modification of the passive of the subordinate clause by the PPs denoting agents, instruments, and causers/causing events. On the whole, this paper finds that Xitsonga passives of the subordinate intransitive clause may be modified by PPs denoting agents, instruments (pure-instruments), and causers (instrument-causers) when the verb in such a clause is a motion verb with a reduplicated stem, or a weather verb, and when the passive morpheme co-occurs with the causative morpheme.
\end{abstract}

Keywords: Anticausatives; passive; intransitive verb; subordinate clause; causative morpheme; perfect morpheme.

\section{Introduction}

In recent literature, anticausatives and causatives have received much attention. Many studies show how the former is different from the latter. Generally, it is argued that, in contrast to their causative counterparts, anticausatives do not contain a thematically unspecified implicit external argument (Alexiadou, Anagnospoulou, and Schäfer 2006: 183). Consider the example below:

$$
\begin{array}{llll}
\text { [Mufana] } & u & \text { fay-a } & \text { [nghilazi] } \\
\text { 1young.man } & \text { SM1 } & \text { break-FV } & \text { 9glass }
\end{array}
$$


"The young man breaks the glass."

In (1) the causative sentence contains a thematically specified explicit external argument, namely, NP mufana 'the young man'. This external subject NP argument mufana 'the young man' in (1) is an agent that brings about the event of breaking the NP nghilazi 'the glass'. In terms of the event semantics, the verb -faya 'break' in (1) contains two subevents, namely, the subevent of breaking the glass, and the resultant state subevent of the broken glass. According to Pustejovsky (1995: 69), these two subevents are temporally ordered and the first subevent precedes the second subevent. It may be possible in Xitsonga to have a causative sentence as in (1) be altered into an anticausative sentence. Such an alternation is made possible by the addition of the neuter-passive morpheme -ek- on the verb. Consider the example below:

$$
\begin{array}{lll}
\text { [Nghilazi] yi } & \text { fay-ek-ile } \\
\text { 9glass } & \text { OM1 } \\
\text { "The glass broke." }
\end{array}
$$

It is clear from the example in (2) above that the neuter-passive morpheme -ek- is a marker of anticausative morphology in Xitsonga. This morpheme marks the absence of an external argument. In Xitsonga, anticausatives, as opposed to passives, do not allow a thematically unspecified implicit external argument to occur with them as agents, instruments, or causers/causing events (Alexiadou, Anagnostopoulou and Schafer 2006: 183). The anticausative sentence below attests to this:

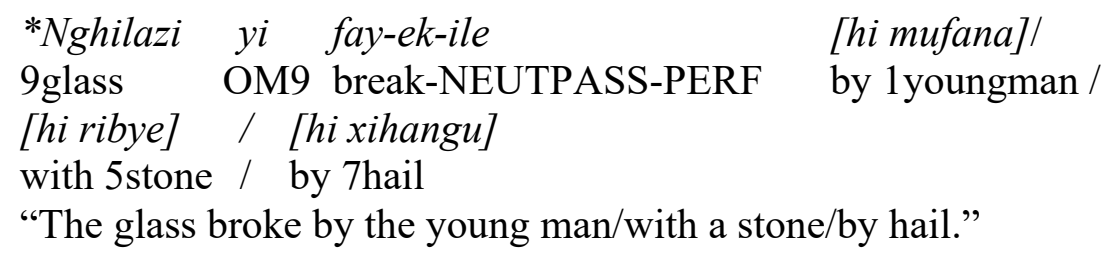

The modification of anticausatives by the PP hi mufana 'by the young man' / hi ribye 'with a stone'/hi xihangu 'by hail' in (3) renders the sentence ungrammatical. However, when anticausatives occur with the subordinate reason clause which contains the passive morpheme -iw-, it may be possible for the PPs - which may be interpreted as agents, instruments, and causers - to modify such a passivized intransitive verb, as example (4) demonstrates below:

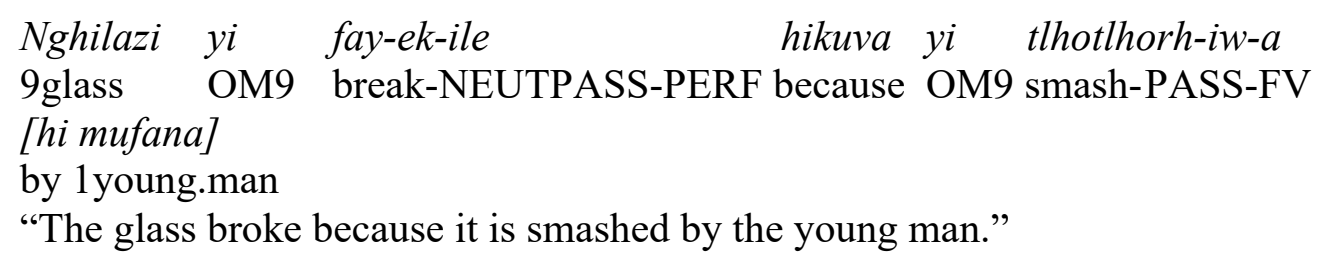

When the subordinate reason clause which contains the passive morpheme -iw- is introduced in (4), the ungrammaticality present in (3) disappears. This passive morpheme de-externalises the external subject NP mufana 'young man' in (4) so that it occupies the position of the internal object NP argument which has been vacated by the original internal object NP nghilazi 'the glass', which has relocated to the external subject NP position. The original external subject NP argument transforms into a PP when it relocates to the position of the object NP argument. Without the passive morpheme -iw-, (4) would look like (5) below: 


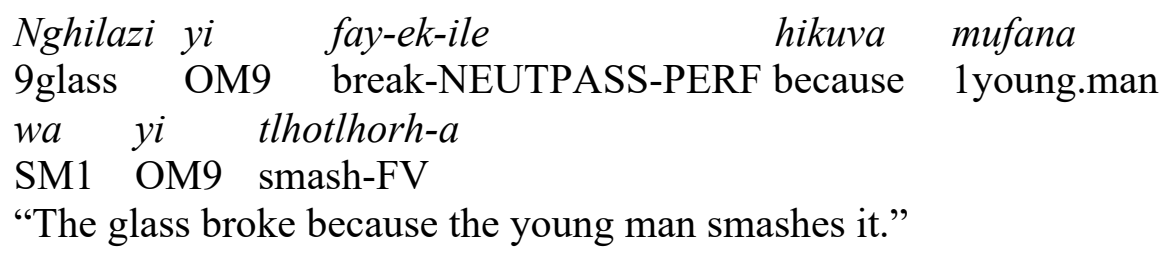

Now that the passive morpheme -iw- has been removed from the verb of the subordinate hikuva 'because' reason clause in (5), the agent PP hi mufana 'by the young man' which modifies the passivized verb in (4) relocates to the position of the external subject NP argument of the subordinate reason clause in (5). In this position, the PP hi mufana 'by the young man' in (4) reverts to its original semantic category of a subject NP and it occurs with both the object and the subject markers. The co-occorrence of the subject and object markers in (5) is obligatory, in order to avoid ungrammaticality. The subject marker serves as the antecedent of the subject NP mufana 'the young man', while the object marker serves as the antecedent of the original object NP nghilazi 'the glass'.

Since intransitive verbs are one-place predicates with only one argument which occupies the external subject position, when the passive morpheme -iw- is added to them, their subject position will be empty, and it will be designated as pro and the agreement in inflection will receive an existential feature marked by ku. This ku existential agreement will be coindexed with the empty pro so that both have the existential feature (Du Plessis, Nxumalo, and Visser 1995: 91). Consider the example below:

$$
\begin{array}{lll}
K u & \text { etler-iw-a hi vana } & \text { e-mu-bedw-eni } \\
15 & \text { sleep-PASS-FV by 2children LOC-AFF-bed-LOC } \\
\text { "There is slept by children on the bed." }
\end{array}
$$

For anticausatives to occur with a subordinate reason clause which contains a passivised intransitive verb, two conditions have to be satisfied. First, the subordinate clause must have an external subject NP argument which should be de-externalised by the passive morpheme -iwso that it occurs as a PP of the passivized intransitive verb. Second, the subordinate clause of the anticuasative must contain an object marker which should be coindexed with the patient/theme argument of the anticausative clause. The structure of the passive of the intransitive clause in (6) above does not satisfy the two stipulated conditions above since it is constituted by only one clause. There is no subordinate clause.

In order for the two mentioned conditions to be satisfied, the sentence must be constituted by two clauses, namely, the anticausative clause and the subordinate passive clause. See the example below:

*Nghilazi yi fay-ek-ile $\quad$ hikuva yi $\quad w$-iw-a
9glass OM9 break-NEUTPASS-PERF because OM9 fall-PASS-FV
[hi mufana]
by 1young.man
"The glass broke because it is caused to fall by the young man."


Although the sentence in (7) is constituted of the two aforementioned clauses, namely the anticausative clause and the subordinate clause with the passive, it is ill-formed. This is because the intransitive verb of the subordinate clause contains the passive morpheme -iw-, without the causative morpheme -is- which accounts for the presence of the agent PP hi mufana 'by the young man'.

When the causative morpheme -is- is added to the intransitive verb of a subordinate clause that already contains a passive morpheme -iw-, the ungrammaticality which is in (7) disappears. The example below illustrates this point:

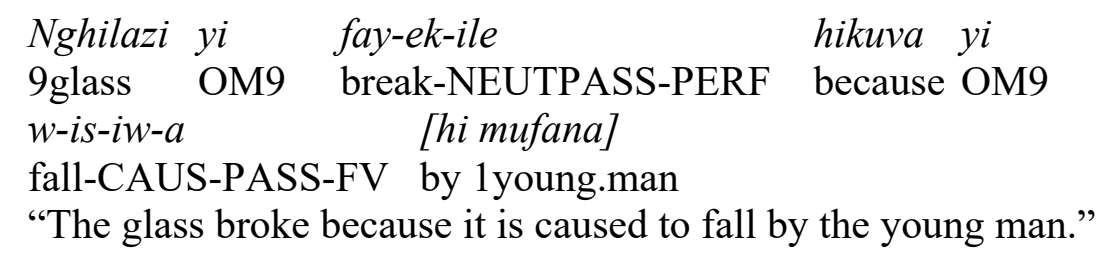

The role of the causative morpheme -is- in (8) has been to introduce the new external subject NP argument mufana 'the young man' within the subordinate reason clause. The passive morpheme -iw- has de-externalised the new external subject agent NP mufana 'the young ma' into the object position. Here it changed from being an NP argument into an agent PP hi mufana 'by the young man' argument of the passivized intransitive verb of the subordinate clause. The sentence in (8) contains two object markers, one in the anticausative clause, and the second in the subordinate passive clause. The second object marker of the patient/theme object NP $n$ ghilazi 'glass' of the anticausative clause is coindexed with the patient/theme NP argument of the anticausative clause. The sentence in (8) satisfied the two conditions stipulated above, hence the sentence is well formed.

This paper focuses on constructions akin to (8), where the anticausative clause occurs in the same sentence as the passivized intransitive reason clause. The passivized intransitive reason clause takes two forms. First, it occurs with the passive morpheme and the causative morpheme. Second, it occurs with the perfect morpheme, in addition to the passive and causative morpheme. The investigation in this paper is conducted following the views of the detransitivisation and the de-externalisation approach. In particular, the detransitivisation approach is employed in situations where the inchoative/anticausative variant occurs without the explicit external argument. The de-externalisation approach, on the other hand, is employed in both situations, namely, with explicit or implicit external argument where it derives passives from causatives. In a way, these two approaches complement each other. This paper will also determine the syntactic status of the PPs in question. That is, it will establish whether the PPs that occur in specific positions are complements or adjuncts of the passivized intransitive verb of the subordinate clause. Furthermore, the paper will examine the effect of the presence or absence of the subject and/or the object markers within the anticausative clause and the passivized intransitive verb of the subordinate reason clause. The data of this paper was collected and analysed using the intuition method as the author is an L1 speaker of Xitsonga. The collected data was verified by making use of students who are first language speakers of Xitsonga, and who are currently studying Xitsonga at the University of Venda. It would have been difficult, if not impossible, to find some of the structures presented in this paper had we used written sources. Furthermore, written sources would have been more relevant if the aim 
was to determine the structures that are used frequently as opposed to those that are not frequently used, which is not the concern of this paper.

The rest of the paper is organised as follows: section 2 presents the background to previous studies related to the topic of this research. Section 3 discusses the by phrase as an agent and/or instrument. Section 4 examines the by phrase as causer. Section 5 provides a summary of the findings of this paper.

\section{Background on the study}

Anticausatives have been extensively investigated in many languages. However, their formation is still problematic, and no adequate analysis has been offered (Kjell 2001). Cross linguistically, what is generally accepted is that a verb like break can have both a causative and an anticasative form (Gluckman and Bowler 2006: 273). The causative alternation is semantically quite well-defined, contrary to the anticausatives (Alexiadou, Anagnostopoupou and Schafer 2006: 178). With regard to anticausatives, languages show a substantial variation in the morphological shape of the alternation (Alexiadou, Anagnostopoupou and Schafer 2006: 178).

According to Poponet (2008: 309), in the inchoative/anticausative alternation, verbs of motion are used non-agentively in the intransitive variant. Alexiadou, Anagnostopoupou and Schafer (2005: 7) argue that verbs that are compatible with inchoative/anticausative alternation are those that have a causative counterpart. That is, those that are externally caused. It has been pointed out that the by phrase is most comfortably used with verbal roots that are unspecified for causation, such as break and open, because they are brought about without external causation (Alexiadou, Anagnospoulou, and Schäfer 2006: 192). Poponent (2008: 309) further notes that most alternating unaccusatives are verbs of change of state. According to Alexiadou, Anagnostopoupou and Schafer (2006: 181) verbs of change of state that describe changes of state that are internally caused cannot participate in the inchoative/anticausative alternation since it would have to derive something from a non-existing base. They use the example below to illustrate their point:
a. The cactus blossomed early
*The gardener blossomed the cactus
*The warm weather blossomed the cactus

It is argued that in many languages, inchoative/anticausative alternation is marked by special morphology (Alexiadou, Anagnostopoupou and Schafer 2006: 179). Consider their examples below:

$$
\begin{aligned}
& \text { a. Russian: kat'-sja 'roll (intr)' (Haspelmath 1993: 91) } \\
& \text { katat' 'roll (tr)' } \\
& \text { b. Polish: złamać się 'break (int)' } \\
& \text { złamać 'break (tr)' }
\end{aligned}
$$

It is evident from (10) that the insertion and/or absence of a specific morpheme results in one verb changing from intransitive to transitive forms, or vice versa. (10a) shows that in Russian, 
the insertion of the morpheme -sja signifies an intransitive use of the verb 'roll', whereas the attachment of the morpheme at signifies a transitive use of the verb 'roll'. Similarly, (10b) indicates that in Polish the attachment of the morpheme -sie yields an intransitive sense of the verb 'break', while the absence of the morpheme -sie signifies a transitive use of the verb 'break'.

Another observation made is that some verbs only have intransitive uses for certain choices of internal arguments, that is, they have restrictions on the kind of internal arguments they can occur with in order to participate in the alternation (Alexiadou, Anagnostopoupou and Schafer, 2006: 180). This point is illustrated by giving examples taken from Levin and Rappaport Hovav (1995: 85-86) as shown below:

(11) a. He broke his promise/the contract/the world record

b. *His promise/the contract/the world record broke

c. He broke the vase

d. The vase broke

While in the active form, the verb broke in (11a) is compatible with internal arguments such as his promise/the contract/the world view, in the passive form the verb broke is incompatible with these internal arguments, hence (11b) is ungrammatical.

It is argued that some verbs, such as break, have both anticausative and passive alternants, while others, such as cut, do not and so lack the anticausative alternant and can only form a passive (Alexiadou, Anagnospoulou, and Schäfer 2006: 180). According to Alexiadou, Anagnostopoupou and Schafer (2006: 180) transitive verbs that cannot form anticausatives restrict their subjects to agents and instruments and disallow causers. Their point is illustrated in the examples below:

(12) a. The baker/the knife cut the bread

b. *The lightning cut the clothesline

c. $\quad *$ The bread cut

(13) a. The vandals/the rocks/the storm broke the window

b. The window broke

Alexiadou and Schäfer (2006: 42-44) distinguish between two types of instruments, namely, pure instruments and instrument-causers. They assert that pure instruments are conceived as strictly auxiliary to the action of the agent by whom they are being employed, while instrumentcausers are conceived as acting on their own. According to these scholars, instrument-causers make good subjects in English as opposed to pure instruments. They provide the examples below:

\section{Pure Instrument}

(14) *The axe broke the window. (Alexiadou and Schäfer 2006: 43)

\section{Instrument-Causers}

(15) The wind/the rain (fall)/cracked the window 
They further point out that pure instruments make good subjects if they are eventive/involved in an (autonomous) event. They give the examples below:

(16) a Die *(runterfallende) Axt zerbrach die Scheibe. (Alexiadou and Schäfer 2006: 44) The down-falling axe broke the pane.

b. Die vliegende steen heeft de ruit gebroken.

The flying stone has the pane broken.

Furthermore, they argue that not all instruments that make good subjects have to be eventive. According to them, there is a class of acceptable instruments that cannot be ascribed autonomous eventivity. They show that this class of instruments relates to the distinction between tools and secondary tools. They argue that only tools can be subjects. The examples below illustrate their point:

\section{(17) The instrument as a PP (tools)}

a. Ashley cut the door with a knife

b. Casey opened the door with the key

(18) The instrument as a subject (tools)

a. This knife cuts the melon easily

b. This key opened the door

(19) The instrument as a PP (secondary tools)

a. Cathryn ate spaghetti with a fork

b. Denis is drinking juice with a straw

(20) The instrument as a subject (secondary tools)

a. $\quad *$ This fork ate spaghetti

b. $\quad *$ This straw is drinking juice

From the perspective of event structure, it has been long established that causatives and inchoatives do not behave like atoms, but have internal events of their own (Pustejovsky 2001: 94 in Bouillon and Busa 2001). In the literature, this is referred to as complex event structure. This structure is constituted of two subevents (Washio 1993: 45; Pustejovsky 1995: 69; Haspelmath 2008: 1; Gluckman and Bowler 2016: 273; Alexiadou, Anagnostopoupou and Schafer 2006: 177; Tatevosov 2013: 199). The two subevents, namely the $\mathrm{e}^{1}$ and the $\mathrm{e}^{2}$, are temporally ordered and the first subevent precedes the second subevent (Pustejovsky 1995: 69). The first subevent entails a causing event while the second subevent signifies a resulting state. In other words, the occurrence of the first subevent leads to the second subevent. In a situation where one event begins, and subsequently gives rise to another process, the first process also continues to take place (Pustejovsky 1995: 73). According to Alexiadou, Anagnostopoupou and Schafer (2006: 190), the CUAS feature is responsible for a causal relation between a causing event and the resulting state denoted by the verbal root + theme.

Addressing the issue of the effect of the perfective morphology on the predicate argument structure, linguists (Singh 2005: 172, Wu 2005: 301) generally agree that the main function of the perfective morpheme is to indicate that the action described by the verb has reached an end. Two traditions have dominated the debate concerning the semantics of the perfect aspect, namely, boundedness theory and totality theory (Savic 2017: 49). In terms of boundedness theory, the perfective aspect indicates that the eventuality is viewed together with its internal limit or the endpoint after which it stops, whereas the contrary is true for totality theory, that is, 
the perfect aspect represents an eventuality as an indivisible whole without making reference to its internal structure (Singh 2005: 172, Savic 2017: 49). Singh (2005: 172) also points out that the two-component theory proposed by Smith (1992) may accommodate various interpretations of the perfective. Singh (2005: 172), citing Smith (1992), postulates that various interpretations may be realised when the perfective is used for non-stative situation types such as achievements, activities, and accomplishments. Kiparsky (1988: 11-13, 2002: 4) distinguishes between five types of readings of the perfect tense/aspect, namely, the existential reading, the universal reading, the resultative reading, the recent past reading, and the present past reading. According to Mittwoch (2008: 323), the first three uses (readings) are most commonly distinguished in literature. In (21) below, Kiparsky (2002: 1) provides example sentences for each of the five identified readings of the perfective:

(21) a. Existential: Fred has visited Paris several times

b. Universal: I have known him since 1960

c. Resultative: The police have probably caught the suspect by now

d. Recent Past: Archduke Ferdinand has been assassinated in Sarajevo ["hot news" June 28, 1914]

e. [Stative Present: I've got (=I have) something to tell you]

Kirpasky (2002: 4) asserts that the existential reading, also referred to as the experiential reading, is realised when the following conditions are satisfied: (i) the whole event denoted by an atelic or iterative telic verbal predicate (state or process) is fully contained in the interval, (ii) the resulting predicate asserts that one or more events of that type occurred during that interval, and (iii) the event does not have to extend throughout the entire interval of $\mathrm{E}$ to the beginning of R. According to Kiparsky (1988: 4-7, 11-13) the existential reading of (20a) is that Fred has visited Paris on one or more occasions during period $\mathrm{E}$ (event time) extending from some past time up to time $\mathrm{R}$ (reference time), and implies that he is not currently visiting Paris.

Furthermore, according to Kiparsky (2002: 4-5) the universal reading, also known as the continuing reading, is obtained when the following two conditions are met: (i) the event denoted by an atelic or iterative telic verbal predicate is coextensive with the interval E. In other words, the state or the process must last for the entire duration of the period terminating at $\mathrm{R}$, (ii) the universal reading requires an adverb specifying a duration, as an example, the sentence in (21b) is interpreted as meaning that the state of knowing extends throughout the entire time from 1960 up to $\mathrm{R}$, which in this case is the present.

Describing the resultative reading, also called the state reading, Kiparsky (2002: 5-6) quantifies that this reading applies only to accomplishment and achievement predicates, which are characterised by change of state. In the case of an accomplishment predicate, it denotes an event consisting of an activity leading to a change of state. In the case of an achievement predicate, it denotes an event of a change of state. The resultative reading of the perfect is obtained when the change of state corresponding to an accomplishment or achievement predicate is temporally located at the edge between time $\mathrm{E}$ and time $\mathrm{R}$ in the perfect's time schemata. In the case of accomplishment predicates, the change of state is temporally located at the onset of time R. This implies that the activity leading up to it must immediately precede R. Using (21c) as an example, Kiparsky (1988: 11, 2002: 6) shows that the activity of pursuing the suspect is located at E. In other words, the activity extends from some time prior to $\mathrm{R}$ up to 
$\mathrm{R}$, while the change of state is located on the edge between $\mathrm{E}$ and $\mathrm{R}$, and the result state commences at that point. With regard to achievement predicates, just like in the case of accomplishment predicates, the change of state is located at the onset of $\mathrm{R}$ time, with the implication that it does not extend throughout the entire interval between the $\mathrm{E}$ and the $\mathrm{R}$, but no activity is located a E.

The recent past reading is described by Kiparsky (2002: 7) as an implicature of the resultative reading. In other words, the recent past and the resultative readings are a special case of a single reading. This is because the resultative reading situates an event at a time which verges on $\mathrm{P}$ (perspective) time, and locates the result state at time P. In other words, the resultative and recent past functions co-occur cross linguistically. To support his views, Kiparsky (2002: 7) argues that the distinction between (21c) and (21d) disappears when the adverbs are removed. This is not so with other examples.

With respect to the present state reading, Kiparsky (2002: 7) points out that the reference interval of this reading is included in the result state corresponding to the verbal predicate. The change of state is not assigned to any temporal parameter, but remains implicit. It is not part of the reading of the perfect, though it may be pragmatically inferred. This gives rise to stative interpretation, and strictly present time reference.

According to Singh (2005: 172), for achievements, the perfective is more natural than the imperfective and signifies the corresponding change of state; for activities, the perfective describes their cessation at any arbitrary point; and for accomplishments the perfective is taken to emphasize the natural ending of the situation. Wu (2005: 302), citing Smith (1997), asserts that the simple perfective viewpoints semantically convey termination, not completion. According to $\mathrm{Wu}$ (2005: 302), Smith further notes that pragmatics have an important role in deciding whether an accomplishment presented by the perfective has a completive reading or a terminative reading. Following Smith (1997), Wu (2005: 302) further contends that the completive interpretation is only conversational, and can be cancelled by other information.

There are contradicting views regarding the relevance of the detrasitivisation approach in analysing anticausatives. According to Alexiadou, Anagnostopoupou and Schafer (2006: 177) the detransitivisation process creates an intransitive entry from a transitive one. Alexiadou, Anagnostopoupou and Schafer (2006: 180) further argue that the logical problem that is faced by this approach is that it would have to derive something from a non-existing base. In support of their view, they give examples of change of state unaccusatives which have no causative counterpart, e.g. bloom, blossom, decay, etc. which involve changes of state that are internally caused, i.e. the cause of the change of state event is linked to the properties inherent to the argument undergoing change. According to them, the internally caused verbs do not have unaccausative counterparts. In their view, the detranstivisation approach may work well with the distribution of PPs in passives. This is the approach adopted in this paper to account for the omission of the PPs modifying the passive. This approach works hand in hand with the deexternalisation approach which accounts for both the explicit external argument which has relocated to the object position and the implicit external arguments.

Most of the issues raised in this section will be discussed in this paper since they are considered the backbone of the ongoing discussions on anticausatives and passives. Since this paper focuses on anticausative/inchoative alternation, the verbs that will be involved in this 
alternation, just like many other languages, are change of state verbs. This is in line with the observation made by Poponent (2008: 309) who points out that most alternating unaccusatives are verbs of change of state. Alexiadou, Anagnostopoupou and Schafer (2006: 181) express the same views when they assert that verbs of change of state that participate in the inchoative/anticausative alternation are the ones that are externally caused. The change of state verb which is used in this paper, namely -faya 'break', is externally caused and has both the anticausative and the passive alternants. Both these alternants will be allowed to occur in a single construction in this paper.

The other issue relates to the distinction made between pure instruments and instrumentcausers. The paper will determine whether only one or both of these instruments may be realised in Xitsonga.

The paper will also investigate how the concept of event structure, specifically the subeventual structure for predicates, takes place in Xitsonga. Furthermore, this paper will determine which of the readings of the perfect aspect highlighted by Kiparsky (1988: 11-13, 2002: 4-7) above are realised with the perfect morpheme in the intransitive verb of the subordinate clause of anticausatives.

\section{The by phrase as an agent and/or instrument}

The aim of this section is to investigate the passives of the intransitive hikuva 'because' reason clauses to find out whether such clauses allow or disallow the occurrence of the PPs denoting agents and instruments. To test this, the intransitive verbs of the subordinate hikuva 'because' reason clause will first be allowed to occur with the passive morpheme -iw- and the causative morpheme -is-, and second, it will be allowed to occur with the perfect morpheme -ile, in addition to the passive morpheme -iw- and the causative morpheme -is-. The role of the subject and/or object marker within the subordinate reason clause will also be examined. The syntactic status and the syntactic positions of the PPs will receive attention, too.

In Xitsonga, intransitive verbs may occur in the subordinate reason clause with the passive morpheme-iw-, the causative morpheme -is-, and the perfect morpheme -ile when such a clause is modified by PPs denoting agents and instruments. Such intransitive verbs are mostly motion verbs, for example, -tlulatlula 'jump repeatedly', -rhurhumela 'tremble/shiver', -ninginika 'shake', -gobagoba 'wobble', and weather verbs, for example, -wa 'fall (of snow)', -na 'fall (of rain)', -hisa 'become hot', -hunga 'blow of wind'. The intransitive verb that will be examined in this section falls under the semantic verb class of motion verbs, specifically the subclass of roll verbs. Roll verbs involve the process of reduplication. In other words, the verb stem of the verb in question is repeated within a single form (for lexical or grammatical purposes) (Du Plessis 1999: 137 citing Trask 1995: 28). Generally, the process of reduplication may bring additional semantic features into the meaning of the verb, such as to express that an action is carried out frequently, or repeatedly, and to express that an action is carried out aimlessly or indiscriminately (Du Plessis 1999: 137). In the case of the verb -tsekatseka 'shake' that is used in this section, the semantic feature of repetition is attested. 


\subsection{The subordinate reason clause with the passive morpheme and the causative morpheme (for the agent/instrument)}

Most verbs in Xitsonga are compatible with the passive morpheme -iw-. The passive morpheme -iw- can occur alone with them to de-externalise the external subject argument. This seems to work well with transitive and ditransitive verbs. With intransitive verbs it is compulsory for the passive morpheme -iw- to occur together with the causative morpheme -is-. In this subsection, the intransitive verb of the subordinate clause of anticausatives will first be allowed to occur with the two morphemes mentioned above, namely the passive morpheme -iw- and the causative morpheme -is-, and second, will be allowed to occur with three morphemes concurrently, namely, the passive morpheme -iw-, the causative morpheme -is-, and the perfect morpheme -ile.

\subsubsection{The subordinate reason clause with two PPs - the agent and the instrument (without the perfect morpheme)}

The presence of the causative suffix -is- and the passive suffix -iw- within the verb of the subordinate clause allows the two PPs, namely agent PP and instrument PP to occur concurrently in the same sentence. Consider the example in (22).

$\begin{array}{lll}\text { Nghilazi yi fay-ek-ile } & \text { hikuva yi } \\ \text { 9glass OM9 break-NEUTPASS-PERF } & \text { because OM9 } \\ \text { tsekatsek-is-iw-a } \quad \text { [hi mufana] } & \text { [hi nhonga] } \\ \text { shake-CAUS-PASS-FV by 1young.man } & \text { with 9stick } \\ \text { "The glass broke because it is shaken by the young man with a stick." }\end{array}$

In (22) above, two PPs occur simultaneously, namely the causative agent PP hi mufana 'by the young man' and the instrument PP hi nhonga 'with a stick'. The PP hi mufana 'by the young man' occupies the position adjacent to the verb. In this position, the agent PP hi mufana 'by the young man' precedes the instrument NP hi nhonga 'with a stick' which occupies the position furthest from the verb. Each of the two morphemes attached to the intransitive verb, namely the passive morpheme -iw- and the causative morpheme -is- has a specific role to play with respect to the occurrence of the agent PP hi mufana 'by the young man' and the instrument NP hi nhonga 'with a stick'. The effect of the causative morpheme -is- is to add a new external subject NP argument (Du Plessis, Nxumalo, and Visser 1995: 46). In (21) the new external subject is the agent PP hi mufana 'by the young man' which has been de-externalised because of the presence of the passive morpheme -iw- on the intransitive verb of the subordinate reason clause. This new subject argument which now occurs as a PP is assigned the semantic role of causative agent since it is the one that causes the shaking of the glass which results in it being broken. That is, it caused the glass to change from its initial state of unbrokenness to the state of brokenness. In (22), the agent PP hi mufana 'by the young man' occurs in the most prominent position. The syntactic positions of the PPs modifying passivized intransitive clauses of anticausatives may be associated with the amount of contributions a particular PP makes towards the change of state of the affected NP argument. We will use the concept of scalarity which was introduced by Karttunen and Peters (1979, cited by Rullmann (1997: 44), in interpreting the meaning of the additive particle even. This concept will also help to explain the association that exists between the amount of contributions each PP argument makes in relation to the positions they occupy. Scalarity weighs the amount of the contributions on an imaginary 
scale from the highest point of contributions to the lowest point of contributions, or from the most contributions to the least contributions (Rullman 1997: 44). Using the concept of scalarity, the order of constituents in (22) may then be interpreted in terms of the amount of contributions they make to the event of the breaking of the NP nghilazi 'the glass'. The agent PP hi mufana 'by the young man' contributes more to the event than the instrument NP hi nhonga 'with a stick'. The PP hi mufana 'by the young man' therefore has an advantage when it comes to the event of shaking of the NP nghilazi 'the glass', which results in it being changed from the state of unbrokenness to the state of brokenness. This implies that in (22) the PP argument understood to have contributed most to the event of shaking the NP nghilazi 'the glass', which resulted in it being changed from the state of unbrokenness to the state of brokenness, is the NP mufana 'the young man'. On the contrary, the PP argument that is construed to have contributed little to the event of shaking of the NP nghilazi 'the glass', which resulted in it being changed from the state of unbrokenness to the state of brokenness, is the instrument NP hi nhonga 'with a stick'. In (22) the agent PP hi mufana 'by the young man' is accorded the syntactic status of a complement because it is compulsory for it to be present. If it is removed and not replaced by the instrument PP, the sentence will be ill-formed. Consider the example below:

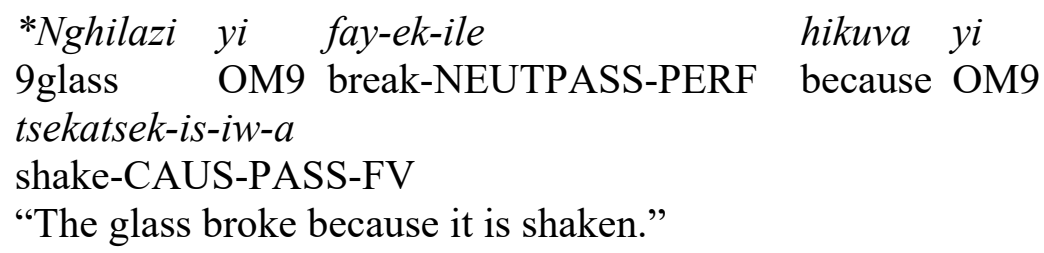

The sentence in (22) may become grammatical when the subordinate reason clause is replaced by the subordinate causative clause. The sentence below exemplifies this fact.

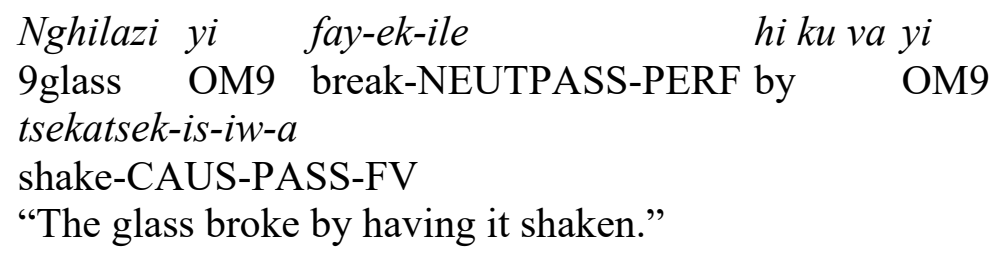

In (24) the reason clause hikuva yi tsekatsekisiwa 'because it is shaken' has been replaced by the causative clause hi ku va yi tsekatsekisiwa 'by having it shaken', hence the sentence is grammatical. In (22) the instrument NP hi nhonga 'with a stick', on the other hand, may be viewed as an adjunct because even if it is removed it will not affect the grammaticality of the sentence. See the example below:

$$
\begin{aligned}
& \text { Nghilazi yi fay-ek-ile } \quad \text { hikuva yi } \\
& \text { 9glass OM9 break-NEUTPASS-PERF because OM9 } \\
& \text { tsekatsek-is-iw-ar [hi mufana] } \\
& \text { shake-CAUS-PASS-FV by lyoung.man } \\
& \text { "The glass broke because it is shaken by the young man." }
\end{aligned}
$$

The instrument NP hi nhonga 'with a stick' which was present in (22) has been removed in (25). Contrary to (22) in which the passive of the intransitive verb of the subordinate reason clause was modified by two PPs, namely the agent PP hi mufana 'by the young man' and the instrument NP hi nhonga 'with a stick', in (25) the passive of the intransitive verb of the 
subordinate clause is modified by only one PP, namely the agent PP hi mufana 'by the young man'. The removal of the instrument PP hi nhonga 'with a stick' does not yield ungrammaticality because it is an adjunct. It is however compulsory for the object marker to be present in (22), otherwise ungrammaticality will result. See the example below:

$$
\begin{aligned}
& \text { * Nghilazi yi fay-ek-ile } \\
& \text { 9glass OM9 break-NEUTPASS-PERF because } \\
& \text { tsekatsek-is-iw-aritha } \\
& \text { shake-CAUS-PASS-FV [hi mufana] [hi nhonga] } \\
& \text { "The glass broke because is shaken by the young man with a stick." }
\end{aligned}
$$

The subject marker, on the other hand, is not needed, as its presence would lead to ungrammaticality. Consider the example below:

$$
\begin{aligned}
& \text { *Nghilazi yi fay-ek-ile } \quad \text { hikuva yi } \\
& \text { 9glass OM9 break-NEUTPASS-PERF because OM9 } \\
& \text { tsekatsek-is-iw-a } \quad u \quad \text { [hi mufana] [hi-nhonga] } \\
& \text { shake-CAUS-PASS-FV SM1 by 1young.man with 9stick } \\
& \text { "The glass broke because it is shaken he by the young man with a stick." }
\end{aligned}
$$

\subsubsection{The subordinate reason clause with two PPs - the instrument and the agent (without the perfect morpheme)}

It may be possible for the agent PP hi mufana 'by the young man' and the instrument NP $h i$ nhonga 'with a stick' in (22) above to swap their positions without affecting the grammaticality of the sentence. This implies that the agent PP hi mufana 'by the young man' will vacate the position adjacent to the intransitive verb of the subordinate clause and occupy the position furthest from the intransitive verb of the subordinate clause. Similarly, the instrument NP $h i$ nhonga 'with a stick' will vacate its initial position which was furthest from the intransitive verb of the subordinate clause to take up the position next to the verb. Consider the example in (28) below:

$$
\begin{array}{llll}
\text { Nghilazi } & y i & \text { fay-ek-ile } & \text { hikuva yi } \\
\text { 9glass OM9 } & \text { break-NEUTPASS-PERF because OM9 } \\
\text { tsekatsek-is-iw- } a & \text { [hi nhonga] [hi mufana] }
\end{array}
$$

shake-CAUS-PASS-FV with 9stick by 1young.man

"The glass broke because it is shaken with a stick by the young man."

The swapping of positions by the two PPs in (22) will result in the instrument NP hi nhonga 'with a stick' being given prominence over the agent PP hi mufana 'by the young man' because it now occurs with the feature of contrastive focus by virtue of it occupying the position adjacent to the verb. The agent PP hi mufana 'by the young man', on the other hand, occurs without the feature of contrastive focus because of its new position which is further from the verb. What has been explained in (22) regarding the presence of the object marker and the absence of the subject marker applies in the same way in (28). It should be noted that the syntactic status of constituents is determined by the kind of positions they occupy. When a particular PP relocates to a new position, it leaves behind the syntactic status it had in that particular position, thereby adopting a new syntactic status in the new position it occupies. Accordingly, the swapping of 
syntactic positions by the agent PP hi mufana 'by the young man' and the instrument NP $h i$ nhonga 'with a stick' in (28) has resulted in them loosing their initial syntactic statuses corresponding to the initial positions they occupied, and thereby adopting new ones which correspond to the new positions they now occupy. The instrument NP hi nhonga 'with a stick' has lost the adjunct status which corresponds to the position furthest from the verb, and adopted the complement status corresponding to the new position which is adjacent to the verb, left by the agent PP hi mufana 'by the young man'. Similarly, the agent PP hi mufana 'by the young man' has lost its initial status of complement by vacating the position adjacent to the verb, thereby adopting the new status of an adjunct, corresponding to the position furthest from the verb which was left by the instrument NP hi nhonga 'with a stick'.

\subsubsection{The subordinate reason clause with the $P P$ as an agent (without the perfect morpheme)}

As illustrated in (25) above, it may be possible for the intransitive verb of the subordinate reason clause which contains the passive morpheme, and the causative morpheme to be modified by only one PP, namely an agent. Below, we consider again the example given in (25):

$$
\begin{aligned}
& \text { Nghilazi yi fay-ek-ile } \quad \text { hikuva yi } \\
& \text { 9glass OM9 break-NEUTPASS-PERF because OM9 } \\
& \text { tsekatsek-is-iw-a [hi mufana] } \\
& \text { shake-CAUS-PASS-FV by 1young.man } \\
& \text { "The glass broke because it is shaken by the young man." }
\end{aligned}
$$

In (29) the de-externalised agent PP hi mufana 'by the young man' has been added to the predicate argument structure of the subordinate reason clause of anticausatives because of the presence of the causative morpheme -is-. In other words, the presence of the agent PP hi mufana 'by the young man' is fully dependent on the presence of the causative morpheme -is-. This implies that if the causative morpheme -is- can be removed from the sentence in (29), the agent PP hi mufana 'by the young man' will have to be removed as well, otherwise ungrammaticality will result. The presence of the object marker is compulsory in (29), otherwise the sentence will become ill-formed. The absence of the subject marker, on the other hand, is welcomed because its presence may lead to ungrammaticality. In (29), the agent PP hi mufana 'by the young man' is assigned the syntactic status of a complement of the subordinate clause because its removal would lead to ungrammaticality.

According to Du Plessis, Nxumalo, and Visser (1995: 46) the agent NP introduced by the presence of the causative morpheme -is- may be interpreted with three readings, namely the causative agent, the permissive agent, and/or the assitive agent. Accordingly, when the agent NP relocates to the object position, and changes into the agent PP as a result of the addition of the passive morpheme -iw- as in (29) above, such an agent relocates with these three readings, the causative agent, the permissive agent, and the assistive agent. What this implies is that the agent PP may be interpreted with any of the three readings, depending on the discourse factors (Du Plessis, Nxumalo, and Visser 1995: 47). The agent PP is interpreted as the causative agent when it is construed as causing the event expressed by the predicate. Consider the example below: 
N'wana u w-is-iw-a [hi mufana]

1child OM1 fall-CAUS-PASS-FV by 1young.man

"The child is caused to fall by the young man."

In (30) the agent PP hi mufana 'by the young man' may be interpreted as causing the patient/theme NP $n$ 'wana 'child' to fall, hence it is assigned the semantic role of causing event. The interpretation of the permissive agent is attested with the agent PP when such an agent allows or permits the action/event described by the predicate to happen. Consider the example below:
Mutirhi u muk-is-iw-a
1worker OM1 go home-CAUS-PASS-FV
[hi murhangeri]
"The employee is allowed to go home by the leader."

In (31) the agent PP hi murhangeri 'by the leader' is construed as giving the worker permission to go home, hence it is interpreted as a permissive agent. The interpretation of the assistive agent PP is realised with the agent PP when it is construed as assisting or helping in the event described by the predicate. See the example below:

Mufana u $\quad$ balek-is-iw-a
1young.man OM1 run.away-CAUS-PASS-FV by 1 wanuna]
"The young man is helped to run away by the man."

In (32) the agent PP hi wanuna 'by the man' is interpreted as assisting the young man to run away, hence it is assigned the semantic role of assistive agent. It should be noted however, that in most cases, the three readings of the agent PP may be attested in a single construction. Consider the example below:

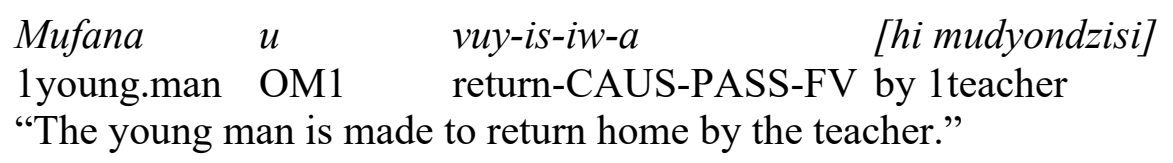

In (33) all the three possible readings, namely the causative agent, the permissive agent, and the assistive agent, are attested in a single sentence. The causative reading of (33) is that the teacher causes the young man to return home. The permissive reading of (33) is that the teacher allows or permits the young man to return home. The assistive reading is that the teacher assists the young man to return home. Based on the identification and description of the three interpretations of the agent PP given above, we can then say that the agent PP hi mufana 'by the young man' in (29) may be interpreted as a causative agent because the young man is construed as the one who performed the shaking of the NP nghilazi 'the glass' which led to its breakage. That is, the causative agent PP hi mufana 'by the young man' shook the glass repeatedly until it broke.

\subsubsection{The subordinate reason clause with the PP as an instrument (without the perfect morpheme)}

It may also be possible for the causative agent PP in (29) above to be replaced by an instrument PP. Consider the example in (34): 


\author{
Nghilazi yi fay-ek-ile hikuva yi \\ 9glass OM9 break-NEUTPASS-PERF because OM9 \\ tsekatsek-is-iw-a [hi nhonga] \\ shake-CAUS-PASS-FV with 9stick \\ "The glass broke because it is shaken with a stick."
}

In (34) the instrument PP hi nhonga 'with a stick' is used by the causative agent PP hi mufana 'by the young man' to shake the patient/theme NP nghilazi 'the glass' to the point where it breaks. The instrument NP hi nhonga 'with a stick' in (34) is treated as a complement because removing it from the sentence would lead to ill-formedness. The object marker is still obligatory in (34) because if it gets removed the sentence will become ill-formed.

Following the distinction made between pure instruments and instrument-causers by Alexiadou and Schäfer (2006: 42-44), we can now diagnose the instrument NP hi nhonga 'with a stick' in (34) above to determine whether it is a pure instrument or an instrument-causer. The diagnosis involves checking whether the instrument NP nhonga 'stick' can perform the action by itself or if it is used by someone/something to perform the action. Consider the example below:

$$
\begin{array}{llll}
\text { [Nhonga leyi] } & y i & \text { tsekatsek-is-a } & \text { nghilazi } \\
\text { 9stick DEM9 } & \text { SM9 } & \text { shake-CAUS-FV } & \text { 9glass } \\
\text { "This stick shakes the glass." } &
\end{array}
$$

The diagnosis in (35) shows that the instrument NP hi nhonga 'with a stick' in (35) is a pure instrument because it has an auxiliary role. That is, it cannot perform the action described in the verb by itself; it has to be used by someone/something to be able to carry out the event.

\title{
3.2 The subordinate reason clause with the causative morpheme, the passive morpheme, and the perfect morpheme
}

In this subsection, two PPs denoting agent and instrument will be allowed to occur with the verb of the subordinate reason clause which contains three suffixes, namely the passive morpheme -iw-, the causative morpheme -is-, and the perfect morpheme -ile.

\subsubsection{The subordinate reason clause with two PPs - the agent and the instrument (with the perfect morpheme)}

It is very typical in Xitsonga for the subordinate reason clause of anticausatives to occur with an intransitive verb that contains the passive morpheme -iw-, the causative morpheme -is- and the perfect morpheme -ile. Their co-occurrence is allowed. Consider the example in (36) below:

Nghilazi yi fay-ek-ile hikuva yi
9glass OM9 break-NEUTPASS-PERF because OM9
tsekatsek-is-iw-ile $\quad$ [hi mufana] [hi nhonga]
shake-CAUS-PASS-PERF by 1young.man with 9stick
"The glass broke because it has been shaken by the young man with a stick."


The example in (36) is partially the same as the example sentence in (22) above. The difference is that in (36) the intransitive verb of the subordinate reason clause occurs with an additional perfect morpheme -ile which was absent in (22). Following Kiparsky's (1988: 11-13, 2002: 47) description of the readings of the perfect aspect, it is clear that the perfect morpheme in the intransitive verb -tsekatseka 'shake' of the subordinate clause in (36) is assigned the existential reading because it satisfies all the three stipulated conditions for this reading, namely, (i) the verbal predicate -tsekatseka 'shake' is atelic, that is, it does not denote a change of state (ii) the whole event of shaking is contained within the intervals $\mathrm{E}$ and $\mathrm{R}$, and (iii) the event of shaking does not continue throughout $\mathrm{E}$ to $\mathrm{R}$. While in (22), the action of shaking the glass is still in progress, in (36) such an action is no longer in progress, it has been terminated. Another difference may be observed in terms of the syntactic status of the PPs. While in (22), the causative agent PP hi mufana 'the young man' was assigned the complement status and the instrument NP hi nhonga 'with a stick' was assigned the adjunct status, in (36) both PPs are assigned the status of an adjunct. This is brought about by the presence of the perfect morpheme -ile. The explanation given in (22) regarding issues such as focus/scope, positions occupied by PPs, and the effect of the presence and/or absence of the object and the subject markers applies similarly in (36).

\title{
3.2.2 The subordinate reason clause with two PPs - the instrument and the agent (with the perfect morpheme)
}

It may be possible in Xitsonga for the two PPs in (36) to swap their positions. Consider the example in (37) below:

\author{
Nghilazi yi fay-ek-ile hikuva yi \\ 9glass OM9 break-NEUTPASS-PERF because OM9 \\ tsekatsek-is-iw-ile [hi nhonga] [hi mufana] \\ shake-CAUS-PASS-PERF with 9stick by 1young.man \\ "The glass broke because it has been shaken with a stick by the young man."
}

The causative agent PP hi mufana 'by the young man' which occupied the position adjacent to the verb in (36) has now vacated that position in (37) and has moved to the position furthest from the verb, which was occupied by the instrument NP hi nhonga 'with a stick'. The instrument NP hi nhonga 'with a stick', on the other hand, has moved from the position it was occupying in (36), which was further from the intransitive verb of the subordinate clause, to occupy the position directly following the verb. This position was previously occupied by the causative agent PP hi mufana 'by the young man' in (36). Once the arguments swap positions, the feature of contrastive focus is also affected because focus corresponds to the arguments that occupy prominent positions. In (36) the focus has shifted from the causative agent PP hi mufana 'by the young man' to the instrument NP hi nhonga 'with a stick' in (37) by virtue of it occupying the position adjacent to the verb. The occurrence of the instrument NP hi nhonga 'with a stick' in the position directly following the verb may be associated with the feature of specificity. That is, it specifies the instrument that was used in carrying out the event of shaking the NP nghilazi 'the glass', which led to the causal subevent of breaking the glass, which also led to the resultant state subevent of the brokenness of the glass. In (37) the two PPs retain their adjunct status, made possible by the presence of the perfect morpheme -ile on the verb of the subordinate clause. The observation made in (22) regarding the presence and/or the absence of the subject and object marker applies similarly in (37). 


\subsubsection{The subordinate reason clause with the $P P$ as an agent (with the perfect morpheme)}

It may be possible for the intransitive verb of the subordinate reason clause which already has two morphemes, namely the passive morpheme and the causative morpheme, to add the perfect morpheme -ile. Consider the example below:

$$
\begin{aligned}
& \text { Nghilazi yi fay-ek-ile } \quad \text { hikuva yi } \\
& \text { 9glass OM9 break-NEUTPASS-PERF because OM9 } \\
& \text { tsekatsek-is-iw-ile } \quad \text { [hi mufana] } \\
& \text { shake-CAUS-PASS-PERF by 1young.man } \\
& \text { "The glass broke because it has been shaken by the young man." }
\end{aligned}
$$

The perfect morpheme -ile, which has been added on the intransitive verb in (38) as opposed to (29) indicates that the event described by the verb -tsekatseka 'shake', which is that of causing the glass to shake, is complete. The effect of the perfect morpheme -ile on the syntactic status of the causative agent PP hi mufana 'by the young man' is that it causes the causative agent PP hi mufana 'by the young man' in (38) to be assigned the syntactic status of an adjunct, in contrast with (29) where the causative agent PP hi mufana 'by the young man' was assigned the syntactic status of a complement. In other words, even if the causative agent PP hi mufana can be removed, it will not affect the grammaticality of the sentence in (38).

\subsubsection{The subordinate reason clause with the PP as an instrument (with the perfect morpheme)}

Just like in (34) above, where the causative agent PP hi mufana 'by the young man' was replaced by the instrument NP hi nhonga 'with a stick' when the intransitive verb of the subordinate reason clause occurred with the passive morpheme -iw- and the causative morpheme -is-, it may be possible for the same replacement to take place when the perfect morpheme -ile, in addition to the passive morpheme -iw- and the causative morpheme -is-, are added to the intransitive verb of the subordinate reason clause of anticausatives. Consider the example below in (39):

$$
\begin{aligned}
& \text { Nghilazi yi fay-ek-ile hikuva yi } \\
& \text { 9glass OM9 break-NEUTPASS-PERF because OM9 } \\
& \text { tsekatsek-is-iw-ile [hi nhonga] } \\
& \text { shake-CAUS-PASS-PERF with 9stick } \\
& \text { "The glass broke because it has been shaken with a stick." }
\end{aligned}
$$

As already pointed out, the effect of the perfect morpheme -ile on the meaning of the verb is to add the feature of complete/concluded. With the perfect morpheme -ile added on a verb that already has the passive morpheme -iw- and the causative morpheme -is- in (39), the difference in meaning between the verb in (34) and (39) is that in (34) the event of breaking the NP nghilazi 'glass' by the instrument NP hi nhonga 'with a stick' is not yet complete, in (39) the event is now complete. The second effect of the perfect morpheme -ile relates to the syntactic status of the instrument NP hi nhonga 'with a stick'. While the absence of the perfect morpheme -ile in (34) allowed the instrument NP hi nhonga 'with a stick' to be interpreted as a complement, its 
presence makes the instrument NP hi nhonga 'with a stick' change from being a complement in (34) to be an adjunct in (39). In other words, even if it can be removed, it will not affect the well-formedness of the sentence in (39). The object marker which plays the role of an antecedent of the NP nghilazi 'the glass' in this sentence is obligatory to occur within the subordinate reason clause. Omitting it from the subordinate clause will result in the sentence being ill-formed. However, its counterpart, namely the subject marker, is not required in (39). Its presence may result in the sentence being rendered ungrammatical.

\section{The by phrase as a causer}

This section aims to examine whether the passives of the intransitive hikuva 'because' reason clauses allow the occurrence of the PPs denoting causers/causing events. Diagnosing this will involve allowing the intransitive verb of the subordinate hikuva 'because' reason clause to first occur with the passive morpheme -iw- and the causative morpheme -is-, and second, to occur with the passive morpheme -iw-, the causative morpheme -is- and the perfect morpheme -ile. The syntactic status and the syntactic positions of the PPs denoting causers will also be involved. Another issue that will be of concern in this section is the role of the subject and object markers within the subordinate clause. In this section, just like in the previous one, only the motion verb -tsekatseka 'shake' belonging to the semantic verb subclass of roll verbs will be used.

\subsection{The subordinate reason clause with the passive morpheme and the causative morpheme (for the causer)}

In this subsection the intransitive verb -tsekatseka 'shake' of the subordinate hikuva 'because' reason clause of anticausatives will be allowed to occur with two morphemes, namely the passive morpheme -iw-, and the causative morpheme -is-, in order to examine whether it may be possible for the passives of the subordinate intransitive clauses of anticausatives to occur with a PP that denotes instrument-causers.

The data indicates that it is possible for PPs to denote instrument-causers which modify the passive intransitive verb of the subordinate hikuva 'because' reason clause, when the passivized intransitive verb occurs with the causative morpheme -is-. Consider the example sentence in (40) below:

$$
\begin{aligned}
& \text { Nghilazi yi fay-ek-ile hikuva yi } \\
& \text { 9glass OM9 break-NEUTPASS-PERF because OM9 } \\
& \text { tsekatsek-is-iw-a [hi mpfumo wa tilo] } \\
& \text { shake-CAUS-PASS-FV by 3thunder } \\
& \text { "The glass broke because it is shaken by the thunder." }
\end{aligned}
$$

Following the distinction made between pure instrument and instrument-causers, there is no doubt that the causer PP hi mpfumo wa tilo 'by thunder' is an instrument-causer because it causes the event described by the predicate by itself. That is, it is not performing an auxiliary function because it is not used by someone/something to carry out the event. The instrumentcauser is different from the agent solely because the agent is an animate entity whereas an instrument-causer is an inanimate entity, specifically a natural force. The sentence in (40) 
occurs with the NP hi mpfumo wa tilo 'by thunder' which refers to the instrument-causer. This sentence is grammatical with the instrument-causer NP hi mpfumo wa tilo 'by thunder'. As pointed out earlier, the role of the passive morpheme -iw- is to de-externalise the external subject argument so that it occurs as an internal argument. This role has been performed accordingly in (40). The causative suffix -is-, on the other hand, added the new external subject NP argument mpfumo wa tilo 'thunder' which has been de-externalised by the passive morpheme -iw- so that it occurs as an instrument-causer NP hi mpfumo wa tilo 'by thunder' modifying the passive of the intransitive verb of the subordinate reason clause of the anticausative. The reason why this new argument is assigned the semantic role of an instrumentcauser is solely because it is the one that causes the event of shaking of the glass which results in the glass changing from the initial state of unbrokenness to the final state of brokenness. In (40) it is obligatory for the object marker to occur within the subordinate clause so that is serves its role of being an antecedent of the patient/theme NP nghilazi 'the glass'. If it is omitted, the sentence will become ill-formed. The subject marker, however, is not required to occur. Its presence will lead to ungrammaticality. The instrument-causer NP hi mpfumo wa tilo 'by thunder' is a complement because it cannot be removed from the sentence, otherwise ungrammaticality will result.

\subsection{The subordinate reason clause with the causative morpheme, the passive morpheme, and the perfect morpheme (for the causer)}

In this subsection the intransitive verb -tsekatseka 'shake' of the subordinate hikuva 'because' reason clause will be allowed to occur with three morphemes, namely, the passive morpheme iw-, the causative morpheme -is-, and the perfect suffix -ile. The aim is to examine whether it may be possible for the PPs that denote instrument-causer to occur as modifiers of the intransitive verb with these three morphemes. The data shows that it may be possible in Xitsonga for a PP that denotes instrument-causer to occur as a modifier of the intransitive verb of a subordinate hikuva 'because' reason clause of anticausatives which contains the three morphemes mentioned above. The example in (41) below attests to this:

$$
\begin{aligned}
& \text { Nghilazi yi fay-ek-ile hikuva yi } \\
& \text { 9glass OM9 break-NEUTPASS-PERF because OM9 } \\
& \text { tsekatsek-is-iw-ile } \quad \text { [hi mpfumo wa tilo] } \\
& \text { shake-CAUS-PASS-PERF by 3thunder } \\
& \text { "The glass broke because it has been shaken by the thunder." }
\end{aligned}
$$

In (41) the NP hi mpfumo wa tilo 'by thunder' occurs as a modifier of the passivised intransitive verb of the subordinate hikuva 'because' reason clause. As already pointed out in (40) above, each of these morphemes, namely, passive morpheme, causative morpheme, and perfect morpheme has a specific role to play regarding the occurrence of the causer PP as a modifier of the passive intransitive verb of the subordinate reason clause of anticausatives. The causative morpheme -is- adds a new argument which occupies the external subject argument position, namely the patient/theme NP mpfumo wa tilo 'thunder'. The passive morpheme -iw- deexternalises this new external subject NP argument mpfumo wa tilo 'thunder' so that it is placed in the internal argument position where it assumes the role of a modifier to the passived intransitive verb of the subordinate reason clause of anticausatives. In this new position, the subject argument NP mpfumo wa tilo 'thunder' transforms into the NP hi mpfumo wa tilo 'by thunder' because of the presence of the passive morpheme. Also in this position, the NP $h i$ 
mpfumo wa tilo 'by thunder' is assigned the semantic role of instrument-causer because it is construed as the one that performs the event of shaking the glass which leads to the changing of the state of the glass from the state of unbrokenness to the state of brokenness. The role of the perfect suffix -ile in (41) is to indicate that the action which was being performed by the NP hi mpfumo wa tilo 'by thunder', namely the shaking of the glass, has been concluded and the glass is broken. While in (40), the instrument-causer NP hi mpfumo wa tilo 'by thunder' was assigned the syntactic status of a complement because of the absence of the perfect morpheme -ile, in (41), the instrument-causer NP hi mpfumo wa tilo 'by thunder' assumes the syntactic status of an adjunct which is necessitated by the presence of the perfect morpheme -ile. In other words, its removal from the sentence will not affect the well-formedness of the sentence. The presence of the object marker within the subordinate reason clause of the anticausative is still obligatory. If omitted, the sentence will result in ungrammaticality. On the other hand, the subject marker is not allowed to occur within the subordinate reason clause of anticausatives. Its presence will render the sentence ungrammatical.

\section{Conclusion}

It was found in this paper that, in Xitsonga, it is possible for the subordinate intransitive clause which contains the passive morpheme -iw- to be modified by PPs denoting agents, instruments (pure-instruments), and causers (instrument-causers) when the verb of such a clause is a motion verb with a reduplicated stem or a weather verb, and when the subordinate intransitive verb occurs with the causative morpheme -is- in addition to the passive morpheme -iw-. The paper found that the two arguments that exchange their positions because of the presence of the passive affix -iw- relocate to new positions while maintaining their original semantic roles. Another issue found is that when the perfect morpheme -ile is added on the verb of the intransitive clause that already has the causative morpheme and the passive morpheme, it induces the feature complete/concluded on the intransitive verb. It has been found that an existential reading of the intransitive verb -tsekatseka 'shake' can be assigned. This is evidenced by the fact that it satisfies all the three stipulated conditions for this reading, namely, (i) the verbal predicate -tsekatseka 'shake' is atelic because it does not involve any change of state, (ii) the whole event of shaking is contained within the intervals E and R, and (iii) the event of shaking does not continue throughout intervals $\mathrm{E}$ and $\mathrm{R}$. The occurrence of this feature on the verb causes the PPs to be accorded the syntactic status of an adjunct, whereas its absence allows the PP to be accorded the status of a complement. However, when the sentence occurs with two PPs, the PP which occupies the position adjacent to the verb is accorded the syntactic status of a complement while the PP that occupies the position further from the verb is accorded an adjunct status. The paper also affirmed the notion of a subeventual structure, in which change of state verbs contain two subevents. It has also been established that the occurrence of two PPs induces the feature of contrastive focus. It has been found that the presence of the object marker within the anticausative clause and the subordinate reason clause is compulsory, whereas the subject marker is not needed in both instances. This paper found that the agent PP modifying the passive is mainly the causative agent, as opposed to the permissive and the assistive agents. 


\section{Abbreviations}

AFF - affix; CAUS - causative; FV - final vowel; LOC - locative; NEUTPASS neuterpassive; OM - object marker; PASS - passive; PERF - perfective; SM - subject marker.

\section{References}

Alexiadou, A., E. Anagnospoulou and F. Schäfer. 2006. The properties of anticausatives crosslinguistically. In M. Franscarelli (ed.) Phases of Interpretation. Berlin: Mouton. pp.187211. https://doi.org/10.1515/9783110197723.4.187

Alexiadou, A. and F. Schäfer. 2006. Instrument subjects are agents or causers. In D. Baumer, D. Montero and M. Scanlon (eds.) Proceedings of the $25^{\text {th }}$ West Coast Conference on Formal Linguistics. Somerville, MA: Cascadilla Proceedings Project. pp. 40-48.

Bouillon, P. and F. Busa. 2001. The Language of Word Meaning. Cambridge: Cambridge University Press.

$\mathrm{Du}$ Plessis, J.A. 1999. Lexical Semantics and the African Languages. Stellenbosch Communications in African Languages 8. Stellenbosch: University of Stellenbosch.

Du Plessis, J.A, N.E. Nxumalo and M. Visser. 1995. Tsonga Syntax. Stellenbosch Communications in African Languages 2. Stellenbosch: University of Stellenbosch.

Gluckman, J. and M. Bowler. 2016. The anticausative alternation in Luragooli. In L. Payne, S. Pacchiarotti and M. Bosire (eds.) Diversity in African languages. Berlin: Language Science Press. pp. 271-289.

Haspelmath, M. 2008. Syntactic Universals and Usage Frequency. Leipzig: Leipzig School on Linguistic Diversity.

Kiparsky, P. 1988. Aspect and the event structure in Vedic. The Yearbook of South Asian Languages and Linguistics 1: 29-61.

Kiparsky, P. 2002. Event structure and the perfect. In D.I. Beaver, L. Casillas Martinez, B.Z. Clark and S. Kaufmann (eds.) The Construction of Meaning. CSLI Publishers. pp. 113-135.

Kjell, J.S. 2001. An Analysis of the anticausative alternation. Available on line http://folk.uio.no/kjelljs (Accessed 07 September 2018).

Mittwoch, A. 2008. The English resulatative perfect and its relationship to the experiential perfect and the simple past tense. Linguistics and Philosophy 31(3): 323-351. https://doi.org/10.1007/s10988-008-9037-y

Poponet, M. 2016. On Causative se, in Globalization and National Identity, Studies on the Strategies of Intercultural Dialoque, Language and Discourse Section. Arhipelag: Arhipelag XXI Press. 
Pustejovsky, J. 1995. The Generative Lexicon. Cambridge: MIT Press.

Rullman, H. 1997. Event, polarity, and scope. In M. Gibson, G. Wiebe and G. Libben (eds.) Papers in Experimental and Theoretical Linguistics. vol. 4. Alberta: University of Alberta. pp 40-64.

Savić, S. 2017. The perfective and imperfective aspects in Xhosa. Stellenbosch Papers in Linguistics Plus 52: 45-72. https://doi.org/10.5842/52-0-713

Singh, M. 1998. On the semantics of the perfective aspect. Natural Language Semantics 6: 171-199.

Tatevosov, S. 2013. Event structure of the anticausative and unaccusative in Russian. In N. Melnik (ed.) Proceedings of IATL 2013. MIT Working papers in Linguistics. pp 189-210.

Washio, R. 1993. When causatives mean passive: A cross-linguistic perspective. Journal of East Asian Linguistics 2(1): 45-90. https://doi.org/10.1007/bf01440583

Wu, J.S. 2005. The semantics of the perfective le and its context-dependency: An SDRT approach. Journal of East Asian Linguistics 14: 299-336. https://doi.org/10.1007/s10831-005$\underline{7077-7}$ 